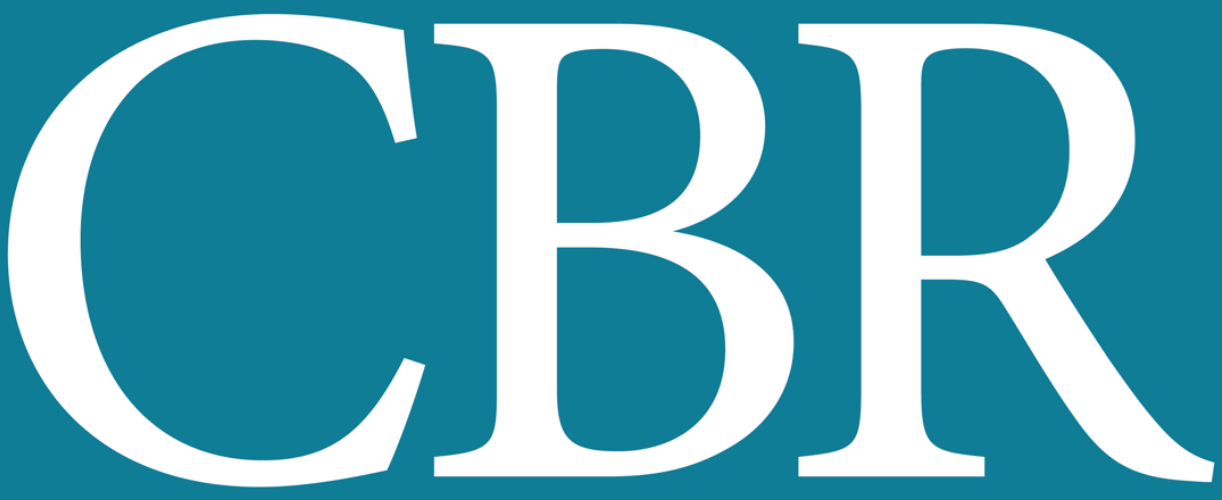

INTERNATIONAL JOURNAL OF CANCER AND BIOMEDICAL RESEARCH

https://jcbr.journals.ekb.eg

Editor-in-chief

Prof. Mohamed Labib Salem, PhD

Blocking angiotensin pathway induces antifibrotic effects in a mouse model of schistosomiasis by decreasing egg burden and granulomatous reaction

Heba A. El-Barabry, Lotfy Z. Habbak, Basem Mansour, Mona Youssef, Amira Taman and Mohamed L. Salem 


\section{Welcome letter from Editor-in-Chief}

Welcome to the Int J Cancer and Biomedical Research (IJCBR)!



It is with great pleasure that I write this editorial to welcome you to the IJCBR. This journal provides a platform for publication of original and reviews research articles, short communications, letter to editor, thesis abstract, conference report, and case studies. These types of publication are directed at the interface of the fields of cancer and biomedical research.

The IJCBR relies on a distinguished expert of the Advisory and Editorial Board Members from the top international league covering in depth the related topics. They timely review all manuscripts and maintain highest standards of quality and scientific methodology and ethical concepts. Meanwhile, we take all possible means to keep the time of the publication process as short as possible.

I take this chance to welcome your contributions to the IJCBR and have every expectation that it will soon become one of the most respected journals in both the fields of cancer and biomedical research.



Mohamed L. Salem,

Editor in Chief 


\title{
Blocking angiotensin pathway induces anti-fibrotic effects in a mouse model of schistosomiasis by decreasing egg burden and granulomatous reaction
}

\author{
Heba A. El-Barabry ${ }^{1}$, Lotfy Z. Habbak ${ }^{1}$, Basem Mansour ${ }^{2}$, Mona Youssef ${ }^{3}$, Amira Taman ${ }^{4}$ and Mohamed L. \\ Salem $^{5}$ \\ ${ }^{1}$ Department of Zoology, Faculty of Science, Damietta University, New Damietta, Egypt \\ ${ }^{2}$ Department of Pharmaceutical Chemistry, Faculty of Pharmacy, Delta University for Science and Technology, Mansoura, Egypt \\ ${ }^{3}$ Department of Pathology, Faculty of Medicine, Mansoura University, Mansoura, Egypt \\ ${ }^{4}$ Department of Medical Parasitology, Faculty of Medicine, Mansoura University, Mansoura, Egypt \\ ${ }^{5}$ Department of Zoology, Faculty of Science, Tanta University, Tanta, Egypt.
}

Background: Schistosoma mansoni infection is associated with hepatic fibrosis and portal hypertension. Previous studies reported that blocking some components of rennin angiotensin system can ameliorate the liver pathology induced by S. mansoni infection. Aim: The present study investigated the potential effect of losartan, an angiotensin II receptor antagonist, and enalapril, an angiotensin-converting enzyme inhibitor, on hepatic fibrosis caused by S. mansoni in a murine model. Materials and Methods: S. mansoni-infected mice were treated at week 5 after infection with losartan, enalapril, or their combination. A group of infected mice was treated with the reference drug praziquantel (PZQ) as controls. Parasitological and histological parameters were investigated. Results: Our results showed that when compared with enalapril, treatment with losartan alone caused a considerable decrease in liver index ( $28.92 \%$ versus $25.09 \%)$, spleen index ( $47.19 \%$ versus $37.08 \%)$, worm burden ( $38.7 \%$ versus $24.8 \%$ ), hepatic tissue egg load (62.7\% versus $54 \%)$, granuloma size (40.4\% versus $29.4 \%$ ) and fibrosis (48.7\% versus $29.4 \%$ ). The combination of losartan and enalapril did not produce a more pronounced effect than those of losartan. Conclusion: Our results suggest the promising effect of enalapril and losartan in amelioration of hepatic pathology but further studies to determine their effects in combination with other antischistosomal agents such as praziquantel are recommended.

Keywords: Angiotensin, Docking, Fibrosis, Liver, Schistosoma mansoni

Editor-in-Chief: Prof. M.L. Salem, PhD - Article DOI: 10.21608/JCBR.2020.50844.1098

ARTICLE INFO



\section{INTRODUCTION}

Intestinal schistosomiasis is a parasitic disease caused by the blood-dwelling parasite, Schistosoma mansoni (Gryseels, 2012). The main pathology of infection with S. mansoni is due to immunological reactions to the eggs released by female worms and trapped in host tissues, including the liver. In the early stages of infection, the inflammatory reaction is reversible, but in the later stages, it is associated with collagen deposition and fibrosis, resulting in organ damage, which could be reversible (Wilson et al., 2007). To date, praziquantel (PZQ) is the only available treatment for all forms of schistosomiasis and causes slight improvement of liver pathology (Berhe et al., 2008).

Hepatic fibrogenesis is a dynamic highly integrated cellular and molecular process caused by multiple etiologies of liver disease, which triggers an integrated signaling network to regulate the extracellular matrix (ECM). In response to this cascade of inflammatory events, which involves mainly the activation of either resident macrophages in the liver (Kupffer cells) and macrophages derived from monocytes, as well as other cells of innate and adaptive immunity. The activation of immune 
cells, occurring through the release of several soluble peptide mediators (cytokines, growth factors, chemokines) and reactive oxygen species (ROS) generation is critical in initiating the activation of hepatic stellate cells (HSC) into myofibroblast-like phenotype, which is proliferative, contractile and fibrogenic (Lee and Friedman, 2011).

Although fibrogenesis and the consequent fibrosis may represent a way to limit the chronic liver injury through the wound healing response to encapsulate the injured cells (Lee and Friedman, 2011), they represent an important factor for the progression of chronic liver diseases (CLD) such as liver cirrhosis and hepatic cell failure (Schuppan and Afdhal, 2008). Moreover, hepatic fibrogenesis and CLD progression are usually linked to persisting angiogenesis with the spread of tissue fibrosis (Tanwar et al., 2020).

For decades, the progression of liver fibrosis to cirrhosis was thought to be unavoidable. However, recent researches identifying the dynamic nature and the mechanism of the fibrosis process had challenged this dogma. Through, utilizing these findings, several novel therapies have been tested in reproducible animal models of liver disease (Sun and Kisseleva, 2015). Although the reninangiotensin system (RAS) is a physiological regulator in the human body, it is involved in chronic tissue damage, and the pathogenesis of hepatic fibrosis and portal hypertension (Shim et al., 2018).

The documentation of a significant relationship between key elements of the RAS (Angiotensin II, Angiotensin II type 1receptor, Angiotensinconverting enzyme) and hepatic fibrosis suggests that countering the effects of the classic RAS axis may have promising therapeutic importance in reducing hepatic fibrogenesis and portal hypertension (Shim et al., 2018). Losartan is an angiotensin II type 1 receptor (AT1) antagonist and enalapril is an angiotensinconverting enzyme (ACE) inhibitor. Both have been shown to reduce hepatic fibrosis caused by various aetiologies (El-Lakkany et al., 2011; Attia et al., 2013; Parreira et al., 2018).

In the current study, we compared the antifibrotic effect of ACE inhibitor and angiotensin II receptor antagonist, using a representative from each group (Enalapril, Losartan) in mice infected with S. mansoni. In addition, we also investigated antischistosomal effects of both drugs. Besides molecular docking simulation of enalapril and losartan was conducted against ACE and angiotensin II type 1receptor respectively to report the binding residues.

\section{MATERIAL AND METHODS Tested Drugs}

Losartan and enalapril were purchased from Sigma-Aldrich, St. Louis, MO, USA). Praziquantel (Biltricide, Alexandria Company for Pharmaceuticals and Chemical Industries, Egypt) was used as a reference drug. Both enalapril and losartan were dissolved in water, while PZQ was dissolved in $2 \%$ Cremophor El (Sigma Chemical Co., St. Louis, USA) by vortexing and then given by oral gavage using a mouse feeding needle, in a volume of 200 $\mu \mathrm{l} / \mathrm{mouse}$.

\section{Animals, parasites, and infection}

Laboratory-bred Swiss albino female mice of CD-1 strain aged 6-8 weeks and weighing 20-22 gm were used in this study. Mice were fed on a standard diet with free accessibility to sterile water and maintained under temperaturecontrolled conditions at $\left(23 \pm 2^{\circ} \mathrm{C}\right)$. Food and water were given ad libitum at the Schistosome Biological Supply Center (SBSC), Theodor Bilharz Research Institute (TBRI), Imbaba, Giza, Egypt. Mice were weighed and infected with freshly shed S. mansoni cercariae, obtained from the SBSC, TBRI, after exposure to light for $30 \mathrm{~min}$. Each mouse was infected with $70 \pm 10$ cercariae by subcutaneous injection (Smithers and Terry 1965). All experiments were approved by the animal ethics committee and carried out at the SBSC/TBRI, in accordance with the international valid animal ethics guidelines.

\section{Animal groups}

Infected mice were randomly allocated into six groups of ten mice each at the beginning of the experiment.

Group A: Non-infected non-treated.

Group B: Infected non-treated.

Group C: Infected and treated with PZQ at a dose of $500 \mathrm{mg} / \mathrm{kg} / \mathrm{day}$. 
Group D: Infected and treated with enalapril (5 $\mathrm{mg} / \mathrm{kg} / \mathrm{d}$ ).

Group E: Infected and treated with losartan (10 $\mathrm{mg} / \mathrm{kg} / \mathrm{d})$.

Group F: Infected and treated with both enalapril $(5 \mathrm{mg} / \mathrm{kg} / \mathrm{d})$ and losartan $(10 \mathrm{mg} / \mathrm{kg} / \mathrm{d})$.

The protocol of treatment for Enalapril and losartan was started at week 5 post-infection (PI) for two consecutive weeks (Wei et al. 2000). But for PZQ, it was given 6 weeks PI for two successive days (Gönnert and Andrews 1977).

Mice were deprived of food $2 \mathrm{~h}$ before drug administration and then allowed to eat $1 \mathrm{~h}$ after drug intake. Nine weeks $\mathrm{PI}$, mice in each group were weighed and then euthanized by intraperitoneal injection of sodium thiopental (100 mg/kg).

\section{Assessment of general parameters and parasitological criteria}

After euthenization, worms were recovered from the hepatic and porto-mesenteric vessels by vascular perfusion technique with subsequent counting. In addition, the liver, spleen, and kidneys from all mice were weighed. The number of eggs per gram of hepatic and intestinal tissues was estimated (Cheever, 1968).

\section{Histopathological studies}

The livers were collected from all mice, washed with phosphate-buffered saline (PBS), sliced into small pieces, and then fixed in $2.5 \%$ glutaraldehyde and $4 \%$ formalin. After liver processing, paraffin sections cut at $4-6 \mu \mathrm{m}$ thickness were stained with hematoxylin and eosin (HE) for granuloma detection and Masson's trichrome for detection of fibrosis. In each histological section, 10 granulomas with visible central eggs were randomly selected; their diameters were measured at $10 \times$ magnification using a calibrated ocular micrometer. Two perpendicular maximal diameters were measured, getting the mean diameter for each granuloma, and then the mean granuloma size in each group was calculated. To quantify hepatic fibrosis, we used the Knodell scoring system (Knodell et al. 1981) applying the following scores: (1) absence of fibrosis; (2) fibrous portal expansion; (3) bridging fibrosis (portal portal or porTable central linkage); (4) cirrhosis. The numerical score obtained for each group was the result of multiplying the grade by the number of mice per grade and then we added these products together for each group.

\section{Dock module of MOE (Molecular Operating Environment)}

In the present study, Dock module of $\mathrm{MOE}$ (Molecular Operating Environment) version MOE 2019.0102, Chemical Computing Group Inc. (MOE., 2019) on a computer having Pentium $1.6 \mathrm{GHz}$ workstation, 512MB memory using windows operating system, was utilized in docking studies. Our tested compounds were drawn into MarvinSketch of Marvin suite (https://chemaxon.com/products) to generate the lowest energy conformer for each. The crystal structure of proteins (receptors); human angiotensin II type1 receptor (PDB;4YAY) (Zhang et al., 2015) human testicular angiotensin Iconverting enzyme (PDB; 1UZE) (Natesh et al., 2004) were obtained from protein data bank (https://www.rcsb.org/). Water molecules were removed from the crystal structure and imported into $\mathrm{MOE}$, at that time, all hydrogen atoms were added to the structure with their standard geometry, followed by their energy minimization. Our tested compounds were docked into the rigid binding pocket of the protein using flexible ligand mode. From ligand conformations, the placement phase generates poses. The free energy of binding of the ligand from a given pose is estimated using the GBVI/WSA $\Delta G$ as a force field-based scoring function (Labute, 2008).

\section{Statistical analysis}

Statistical comparisons were done between infected treated groups and the infected untreated control group. The percentage of the difference between the treated group and the untreated control group was assessed using the formula: (mean value of the untreated group-mean value of the treated group) $\times 100 /$ mean value of the untreated group. Statistical Package for Social Sciences (SPSS) software (SPSS Inc., Chicago, USA) version 16.0 was used for data analysis. Descriptive statistics including the mean \pm SD were used. A nonparametric Mann-Whitney $U$ test was used to test for significant differences between 
groups. $P$ values of $<0.05$ were considered statistically significant.

\section{RESULTS}

Ameliorative effects of losartan and enalapril on total body weight of Schistosoma-infected mice

In this study, the non-infected non-treated mice expressed a significant increase $(P=0.004)$ in the total body weight measured at the end of the study compared with the infected non-treated mice. In contrast, S. mansoni-infected mice treated with $\mathrm{PZQ}$, losartan alone, or combined with enalapril showed a non-significant increase in the total body weight, showing $0.25 \%, 2.62 \%$, $9.13 \%$, respectively, as compared with infected non-treated mice. While infected mice received enalapril alone showed a significant increase in the total body weight $(P<0.05)$ as compared with the infected non-treated mice (Table 1).



A) Losartan<smiles>CCOC(=O)[C@H](CCc1ccccc1)N[C@@H](C)C(=O)N1CCC[C@H]1C(=O)O</smiles>

B) Enalapri

Figure 1. Structure of (A) losartan and (B) enalapril.
Ameliorative effects of losartan and enalapril on the liver index of Schistosoma-infected mice

Infection of mice with $S$. mansoni significantly $(P<0.001)$ increased the liver index (liver weight $\times 100 /$ body weight) compared with noninfected non-treated mice. A single administration of $\mathrm{PZQ}$, enalapril or losartan, or both enalapril and losartan caused a significant $(\mathrm{P}<0.001)$ reduction in the liver index by $12.61 \%, 25.09 \%, 28.92 \%$, and $33.25 \%$, respectively, in comparison with the infected non-treated group (Table 1).

\section{Ameliorative effects of losartan and enalapril} on spleen index of Schistosoma-infected mice

Infection of mice with $S$. mansoni significantly $(P<0.001)$ increased spleen index (spleen weight $\times 100$ /body weight) compared with noninfected non-treated mice. A single administration of $\mathrm{PZQ}$, enalapril or losartan, or both enalapril and losartan caused a significant $(P<0.001)$ reduction in spleen index by $29.21 \%$, $37.08 \%, 47.19 \%$, and $35.96 \%$, respectively, in comparison with the infected non-treated group (Table 1 ).

\section{Ameliorative effects of losartan and enalapril on the worm burden of Schistosoma-infected mice}

There was a significant reduction in the total worm burden after treatment with PZQ, losartan alone, and losartan in combination with enalapril by $86.9 \%, 38.7 \%, 43 \%$, respectively, as compared to infected nontreated mice (Table 2). Interestingly, treatment of infected mice with enalapril did not significantly alter the worm burden (Table 2).

Table 1. Effect of enalapril, losartan or combination on total body weight, liver index, and spleen index in Schistosoma mansoni-infected mice

\begin{tabular}{llll}
\hline Animal groups (No. of mice) $^{\mathrm{N}}$ & Total body weight $(\mathbf{g m})$ & Liver index & Spleen index \\
\hline Non-infected non-treated $(n=10)$ & $22.40 \pm 0.97(10.62)^{*}$ & $5.92 \pm 0.59$ & $0.4 \pm 0.04$ \\
Infected non-treated $(n=10)^{2}$ & $20.25 \pm 1.67$ & $7.85 \pm 0.70(32.6)^{* *}$ & $0.89 \pm 0.22(122.5)^{* *}$ \\
PZQ $(n=10)$ & $20.3 \pm 1.33(0.25)$ & $6.86 \pm 1.11(12.61)^{*}$ & $0.63 \pm 0.09(29.21)^{*}$ \\
Enalapril $5 \mathrm{mg} / \mathrm{kg} / \mathrm{d}(n=10)^{1}$ & $23.22 \pm 2.68(14.67)^{*}$ & $5.88 \pm 0.68(25.09)^{*}$ & $0.56 \pm 0.12(37.08)^{*}$ \\
Losartan $10 \mathrm{mg} / \mathrm{kg} / \mathrm{d}(n=10)^{1}$ & $20.78 \pm 2.44(2.62)$ & $5.58 \pm 0.89(28.92)^{*}$ & $0.47 \pm 0.14(47.19)^{*}$ \\
Enalapril $5 \mathrm{mg} / \mathrm{kg} / \mathrm{d}$ and Losartan $10 \mathrm{mg} / \mathrm{kg} / \mathrm{d}(n=10)$ & $22.1 \pm 3.38(9.13)$ & $5.24 \pm 1.03(33.25)^{*}$ & $0.57 \pm 0.14(35.96)^{*}$ \\
\hline
\end{tabular}

$\mathrm{N}$ : number of mice dead. Values are expressed as means \pm SD. Values between parentheses refer to the percentage of difference compared with the infected non-treated group. "Significant difference from infected non-treated group at $P<0.05 .{ }^{* *}$ Significant difference from noninfected non-treated group at $P<0.05$. 
Ameliorative effects of losartan and enalapril on tissue egg load of Schistosoma-infected mice

The results of egg burden per gram of tissues (liver and intestine) revealed that PZQ induced a higher reduction in the hepatic $(72.59 \%)$ and intestinal (69.19\%) egg load when compared with treatment with enalapril or losartan. A single treatment with enalapril, losartan, or their combination induced statistically significant $(P<0.001)$ reduction in the hepatic egg load by 54\%, 62.7\%, and 55.8\%, respectively, as well as in small intestinal egg burden by $65.76 \%, 49.3 \%$ and $59.7 \%$, respectively, as compared with the infected non-treated mice (Table 3).

Ameliorative effects of losartan and enalapril on the liver granulomatous reaction of Schistosoma-infected mice

Liver from non-infected mice showed normal architecture with no inflammatory cells (Figure 2a). While liver sections from infected nontreated mice showed large granuloma composed of numerous macrophages, lymphocytes and fibroblasts were seen (Figure 2b). Medium-sized granulomata with mild inflammation of the liver tissue were seen with PZQ and enalapril treatment respectively when compared with infected non-treated mice (Figure 2c, d). On the other hand, liver sections from mice treated with losartan showed smaller granuloma with less inflammation, compared with infected non-treated mice (Figure 2e) but infected mice treated with the combination of enalapril and losartan showed moderate granuloma with moderate inflammatory reaction ((Figure 2f).

Significant reduction in granuloma count was observed with the group treated with PZQ and combined enalapril with losartan (Table 4), with maximum reduction was observed with the group treated with PZQ (51.23\%). In addition, the reduction in groups treated with enalapril or losartan was nearly the same ( $P>0.05,29.4 \%$, and $29.7 \%$, respectively) as shown in (Table 4 ). According to the observations made on the Masson trichrome stained sections, normal liver revealed no fibrosis (Figure 3a), while, marked fibrosis was seen in infected non-treated mice
(Figure 3b), PZQ and enalapril-treated mice, both showed moderate periportal fibrosis (Figure $3 c, d$ ). Mice treated with losartan alone showed minimal periportal fibrosis surrounding Schistosoma ova (Figure 3e) but mild periportal fibrosis was seen when losartan was used in combination with enalapril (Figure $3 f$ ).

The score of fibrosis was lower in all treated groups, with more reduction in the group treated with losartan monotherapy (Table 5).

\section{Dock module of MOE (Molecular Operating Environment)}

The docking results of enalapril and losartan against human testicular angiotensin Iconverting enzyme (PDB; 1UZE) and human angiotensin II type1 receptor (PDB;4YAY) respectively, are shown in Table 6.

\section{DISCUSSION}

Intestinal schistosomiasis is a granulomatous disease associated with high serum and granuloma angiotensin-converting enzyme (ACE) activity. PZQ, the only available drug for the treatment of schistosomiasis slightly improves liver pathology (Berhe et al., 2008). Therefore, exploring other drugs, which can ameliorate liver pathology, is of paramount significance. Hepatic stellate cells (HSCs) are mesenchymal cells with contractile cytoplasmic processes that can regulate sinusoidal blood flow and are known to play a major role in hepatic fibrosis and seem an ideal drug target for improving liver fibrosis (Rippe, 1998).

In normal liver, HSCs do not express ANGII type 1 (AT1) receptors nor do they secrete ANGII. Following chronic liver injury, HSC transforms into myofibroblast-like cells and express both ANGII type 1 (AT1R) receptors and generate mature ANGTII, which contributes to portal hypertension and increases the proliferation and collagen synthesis in HSCs. Blocking the effects of ANGTII and hence improving hepatic fibrosis can be achieved in two ways, either by blocking the conversion of ANGTI to ANGTII through an angiotensin-converting enzyme inhibitor (ACEI) or by blocking the target receptor via ANG II receptor blocker (ARB) (Shim et al., 2018). 




a)



c)



e)



b)

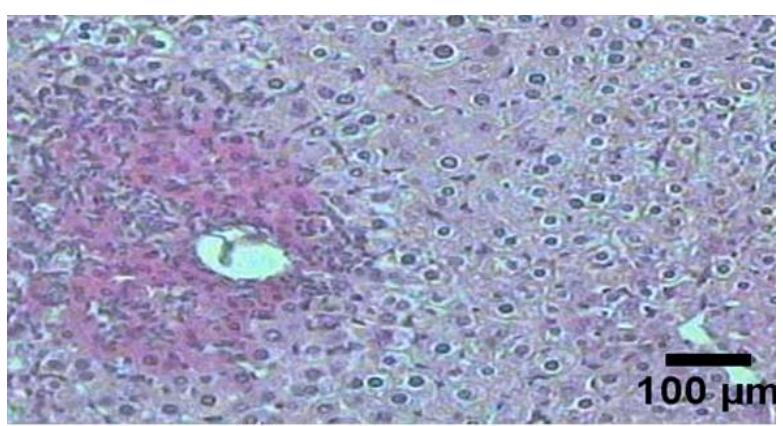

d)



f)

Figure 2. Histopathological study of liver sections of mice infected with Schistosoma mansoni and euthanized nine weeks PI (Hematoxylin and Eosin). (a) Non-infected mice showing normal histology (b) Liver tissue from infected non-treated mice showing extensive interstitial inflammatory cellular infiltrate with some necrotic hepatocytes, together with obvious granulomatous reaction, showing central bilharzial ova surrounded by inflammatory cells and fibrosis. (c) Liver tissue from infected PZQ-treated mice showing moderate granulomatous inflammatory reaction with bilharzial ova surrounded by inflammatory cells and fibrosis. The surrounded liver tissue is more or less normal, with mild inflammatory cells. (d) Liver tissue from infected enalapril-treated mice showing mild inflammatory changes; the granuloma is moderate in size and cells are inflammatory. (e) Liver tissue from infected losartan-treated mice showing a small granulomatous reaction around the degenerated egg. (f) Liver tissue from infected enalapril and losartan-treated mice showing moderate inflammatory changes; the granuloma is moderate in size and surrounded by inflammatory cells. Arrows point to the ova in the granuloma.

Table 2. Effect of enalapril, losartan or their combination on adult worm burden in Schistosoma mansoni-infected mice

\begin{tabular}{|c|c|}
\hline Animal groups (No. of mice) ${ }^{N}$ & Adult worm burden \\
\hline Infected non-treated $(n=10)^{2}$ & $32.20 \pm 4.50$ \\
\hline PZQ $(n=10)$ & $4.21 \pm 2.25(86.9 \%)^{*}$ \\
\hline Enalapril $5 \mathrm{mg} / \mathrm{kg} / \mathrm{d}(n=10)^{1}$ & $24.20 \pm 13.50(24.8)$ \\
\hline Losartan $10 \mathrm{mg} / \mathrm{kg} / \mathrm{d}(n=10)^{1}$ & $19.75 \pm 7.84(38.7)^{*}$ \\
\hline Enalapril $5 \mathrm{mg} / \mathrm{kg} / \mathrm{d}$ and Losartan $10 \mathrm{mg} / \mathrm{kg} / \mathrm{d}(n=10)$ & $18.38 \pm 7.84(43)^{*}$ \\
\hline
\end{tabular}

$\mathrm{N}$ : number of mice dead. Values are expressed as means \pm SD. Values between parentheses refer to the percentage of reduction compared with the infected non-treated group. ${ }^{*}$ Significant difference from the infected non-treated group at $P<0.0001$. 




a)



d)

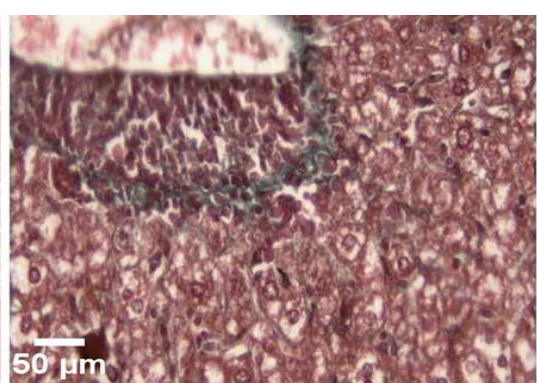

b)

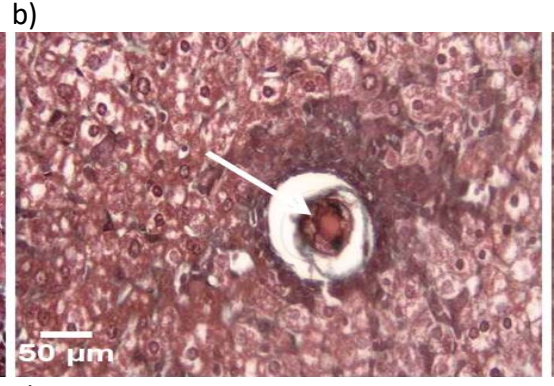

e)



c)



f)

Figure 3. Histopathological study of liver sections of different groups of mice euthanized 9 weeks after the beginning of the study (Masson's trichrome). (A) Non-infected mice showing no pathology. (B) Infected non-treated mice showing mild periportal fibrosis with extensive portal inflammatory cells. (C) Infected mice treated with PZQ showing irregularly outlined fibrocellular granuloma, with moderate collagen deposition, surrounding a partially degenerated ovum. (D) Infected mice treated with enalapril showing moderate periportal fibrosis with extensive portal inflammatory cells. (E) Infected mice treated with losartan showing mild periportal fibrosis with portal inflammatory cells surrounding the ova. (F) Infected mice treated with the combination of enalapril and losartan showing small-sized fibrocellular granuloma with more collagen deposition, surrounding a partially degenerated ovum.

Table 3. Effect of enalapril, losartan or combination on hepatic and intestinal egg load in Schistosoma mansoni-infected mice

\begin{tabular}{lcc}
\hline Animal groups $($ No. of mice) & \multicolumn{2}{c}{ Tissue egg load } \\
& Hepatic egg load/gm $\times \mathbf{1 0}^{\mathbf{3}}$ & Intestinal egg load/gm $\times \mathbf{1 0 ^ { \mathbf { 3 } }}$ \\
\hline Infected non-treated $(n=10)^{2}$ & $17.88 \pm 1.72$ & $16.78 \pm 1.64$ \\
PZQ $(n=10)$ & $4.9 \pm 1.19(72.59)^{*}$ & $5.2 \pm 1.32(69.19)^{*}$ \\
Enalapril $5 \mathrm{mg} / \mathrm{kg} / \mathrm{d}(n=10)^{1}$ & $8.22 \pm 1.39(54)^{*}$ & $5.78 \pm 0.97(65.76)^{*}$ \\
Losartan $10 \mathrm{mg} / \mathrm{kg} / \mathrm{d}(n=10)^{2}$ & $6.67 \pm 0.71(62.7)^{*}$ & $8.65 \pm 2.18(49.3)^{*}$ \\
Enalapril $5 \mathrm{mg} / \mathrm{kg} / \mathrm{d}$ and Losartan $10 \mathrm{mg} / \mathrm{kg} / \mathrm{d}(n=10)$ & $7.9 \pm 1.91(55.8)^{*}$ & $6.8 \pm 2.09(59.7)^{*}$ \\
\hline
\end{tabular}

$\mathrm{N}$ : number of mice dead. Values are expressed as means \pm SD. Values between parentheses refer to the percentage of reduction compared with the infected non-treated group. ${ }^{*}$ Significant difference from the infected non-treated group at $P<0.0001$.

Table 4. Effect of enalapril, losartan or combination on granuloma count and diameter in Schistosoma mansoni-infected mice

\begin{tabular}{lcc}
\hline Animal groups (No. of mice) $)^{\mathrm{N}}$ Granuloma diameter $(\boldsymbol{\mu m})$ & Granuloma count & \\
\hline Infected non-treated $(n=10)^{2}$ & $1090 \pm 240$ & $30.6 \pm 7.6$ \\
PZQ $(n=10)$ & $763.33 \pm 76.16(6.05)^{*}$ & $6.53 \pm 2.01(51.23)^{*}$ \\
Enalapril $5 \mathrm{mg} / \mathrm{kg} / \mathrm{d}(n=10)^{1}$ & $770 \pm 230(29.4)^{*}$ & $21.60 \pm 9.10(29.4)$ \\
Losartan $10 \mathrm{mg} / \mathrm{kg} / \mathrm{d}(n=10)^{2}$ & $650 \pm 180(40.4)^{*}$ & $21.5 \pm 7.2(29.7)$ \\
Enalapril $5 \mathrm{mg} / \mathrm{kg} / \mathrm{d}$ and Losartan $10 \mathrm{mg} / \mathrm{kg} / \mathrm{d}(n=10)$ & $710 \pm 280(34.9)^{*}$ & $15.7 \pm 11.2(48.7)^{*}$ \\
\hline
\end{tabular}

$\mathrm{N}$ : number of mice dead. Values are expressed as means $\pm S D$.Values between parentheses refer to the percentage of reduction compared with infected non-treated group. . Significant difference from the infected non-treated group at $P<0.0001$.

Table 5. Effect of enalapril, losartan or their combination on fibrosis grade in Schistosoma mansoni-infected mice

\begin{tabular}{ccccccc}
\hline & Group B & Group C & Group D & Group E & Group F & P-value \\
\hline Grade I & $1.00 \pm 0.0$ & $4.76 \pm 2.12$ & $4.80 \pm 2.68$ & $3.57 \pm 0.98$ & $2.83 \pm 0.98$ & 0.054 \\
Grade II & $10.60 \pm 4.39$ & $5.82 \pm 2.11$ & $6.60 \pm 3.51$ & $5.83 \pm 3.87$ & $8.33 \pm 2.50$ & 0.176 \\
Grade III & $6.00 \pm 1.23$ & $5.81 \pm 3.43$ & $5.20 \pm 4.32$ & $4.00 \pm 3.08$ & $8.00 \pm 5.02$ & 0.381 \\
Grade IV & $13.80 \pm 6.69$ & $6.56 \pm 3.18$ & $6.25 \pm 2.99$ & $6.00 \pm 4.85$ & $2.33 \pm 1.51$ & 0.005 \\
Total grades & $30.60 \pm 7.60$ & $22.95 \pm 7.14$ & $21.60 \pm 9.10$ & $15.70 \pm 11.22$ & $21.50 \pm 7.29$ & 0.083 \\
\hline
\end{tabular}





Figure 4. The putative binding mode of enalapril onto human testicular angiotensin I-converting enzyme (PDB;1UZE).


Figure 5. The putative binding mode and affinity of losartan onto human angiotensin II type1 receptor (PDB; 4YAY).

Table 6. The highest binding free energy of both enalapril and losartan against their corresponding receptors

\begin{tabular}{ccc}
\hline & $\begin{array}{c}\text { Enalapril against human testicular angiotensin I- } \\
\text { converting enzyme(PDB; 1UZE) }\end{array}$ & $\begin{array}{c}\text { Losartan against Human angiotensin II } \\
\text { type1 receptor (PDB;4YAY) }\end{array}$ \\
$\begin{array}{c}\text { MolDock score } \\
(\mathrm{Kcal} / \mathrm{mol})\end{array}$ & -14.8558445 & -11.334281 \\
\hline
\end{tabular}

Previous work reported improvement of hepatic fibrosis either by inhibition of an angiotensin-converting enzyme (ACE) or blocking of angiotensin II receptors (El-Lakkany et al. 2011; Attia et al. 2013; Parreira et al. 2018). Herein, the hepatoprotective effects and the antischistosomal effects of enalapril and losartan or their combination in S. mansoniinfected mice have been tested.

In the present study, administration of losartan or losartan combined with enalapril resulted in a slight increase in the body weight, but enalapril alone caused a significant increase in the body weight, which is probably related to the amelioration of the liver conditions and general body health.

In schistosomiasis hepatic congestion and portal hypertension are associated with splenic congestion. The reduction in liver index seen in the present study could be attributed to the reduction in the granuloma number and size in addition to the decreases in the portal tract pathology and portal hypertension with a subsequent reduction in the splenic index. Our data showed that the reduction in these two indices was more pronounced after losartan administration. 
The reductions in the liver index reported in our study is nearly similar to our recent studies after treatment with PPQ-8 at 20 and $40 \mathrm{mg} / \mathrm{kg}, 7 \mathrm{~W}$ $\mathrm{PI}$, which induced reduction in the liver index by $23.3 \%$ and $32.8 \%$ respectively (Taman et al., 2020a), or after treatment with PPQ-6 as 20 and $40 \mathrm{mg} / \mathrm{kg}$, 7W PI, which induced reduction by $24.77 \%$ and $35.6 \%$ respectively (Taman et al., 2020b)

The reductions in the spleen index reported in this study are nearly similar to those described by (Lescano et al., 2004). They reported a significant reduction in the spleen index by $38.08 \%$ and $40.63 \%$ in S. mansoni-infected Balb/c female mice treated with artemether at 50 and $100 \mathrm{mg} / \mathrm{kg} 20$ days after infection, respectively.

Besides, two studies conducted in our laboratory reported a nearly similar reduction of spleen index after administration of the compounds PPQ-8 and PPQ-6 (Taman et al., 2020a,b). Interestingly, PZQ induced $29.21 \%$ reduction in the spleen index, which is lower than those reported previously (Liang et al., 2011 and Alhusseiny et al., 2017). The differences between our studies and these studies could be attributed to the strain of mice used, species of schistosomes, and infective dose of cercaria.

In the present study, treatment with losartan alone, but not enalapril alone, or in combination with enalapril resulted in significant reductions in the total worm burden as compared with the infected untreated controls. But enalapril caused an insignificant reduction. In S. mansoniinfected mice, there was a decrease in the protein production of TGF $\beta 1$, the main factor used by angiotensin II for the activation of HSC in animals treated with losartan (Parreira et al., 2018).

The same pathway could act in adult schistosomes leading to a reduction in TGF $\beta$ 1level. The vital roles for the TGF- $\beta$ signaling pathway throughout the schistosome life cycle, especially in female reproductive development and egg embryogenesis involving the vitelline cells were reported (Loverde et al., 2007); consequently, the decrease in the worm count could be attributed to these effects of TGF- $\beta$ produced by the host cells.
In the present study, treatment of S. mansoniinfected mice with $\mathrm{PZQ}$ resulted in a reduction of hepatic and intestinal egg load due to its lethal effect on adult worms with the cessation of oviposition. We found that mice treated with enalapril or losartan or their combination showed a reduction in granuloma count, probably due to the reduction of worm burden and cessation of egg deposition after treatment. In addition, significant reductions in the mean granuloma diameters as well as in the fibrosis were also observed after each treatment. These results are in accordance with the results obtained previously (El-Lakkany et al., 2011), who showed that losartan resulted in some healing of the granulomatous hepatic lesions in S. mansoni-infected mice as could be observed from a reduction in the mean granuloma diameter. The authors suggested an antiinflammatory pathway through which the drug might have suppressed the immune-mediated reaction to oviposition (El-Lakkany et al., 2011). In addition, activation of HSC with chronic schistosomiasis and increased expression of AT1 receptors to bind angiotensin II would stimulate fibrogenesis through TGF- $\beta 1$ (Singh et al., 2004), so interference of this pathway will lead to a reduction in fibrosis as reported.

The reduction in the granuloma size, following PZQ treatment obtained in the study, was lower than that reported by Botros et al. (1986) and may be due to different drug regimens and experimental design. The results presented in this work showed that losartan is more effective than enalapril in improving parasitological parameters and fibrosis in S. mansoni-infected mice. These results are nearly similar to those of Kim et al. (2008) who reported that ARB are superior to ACE inhibitors in the suppression of hepatic fibrosis in bile duct-ligated rat model. The combination of drugs, losartan, and enalapril did not result in more improvement, which might indicate both are not working synergistically.

In this study, virtual screening and molecular docking have been employed to investigate the mechanism of the renin-angiotensinaldosterone system (RAAS) blockade with the combination of two commonly used RAAS blockers; enalapril and losartan ( $\mathrm{Ma}$ et al., 2010). 
The interaction map and configurational hints revealed by the $2 \mathrm{D}$ and $3 \mathrm{D}$ binding simulation established by molecular docking of expected ligand substrate complex provides substantial insights regarding the interaction fingerprints from the tested compounds and top hits of interacting amino acid residues from the polypeptide. The hydrophobic fitting points inside the receptor pocket created at the initial step of docking steered the positioning of ligand hydrophobic moieties. These points created upon the Lennard-Jones potential between a carbon probe and each atom of the residues delimitated the binding site (Nurisso et al., 2012).

By analyzing the interaction map of the Enalapril compound as a ligand and human testicular angiotensin I-converting enzyme (PDB; 1UZE) (Natesh et al., 2004), as shown in Figure4, five hydrogen bonds were seen to be established between ligand and conserved amino acids in the pocket core of the receptor; ester carbonyl and with His513, carboxylic hydroxyl with Tyr523, carboxylic carbonyl with Arg522, free carbonyl with Ser355 and nitrogen atom with Ala354. All these $\mathrm{H}$-bonds besides hydrophilic and hydrophobic interaction have led to an increase in the stability of ligand/receptor complex with the highest binding free energy $14.8558445 \mathrm{Kcal} / \mathrm{mol}$ exhibiting a good binding mode and affinity profile as seen in Fig 4 (3D).

On the other hand, the docking results of losartan against human angiotensin II type1 receptor (PDB;4YAY) (Zhang et al 2015), revealed that the conserved amino acid Arg167 at the hot spot of the receptor pocket acted like a wedge to fix the ligand into the pocket with $\mathrm{H}$ bond with the oxygen of the hydroxyl group of the ligand and another bifurcated $\mathrm{H}$-bond connecting two vicinal nitrogen atoms in the tetrazole ring. Moreover, $\mathrm{H}$-arene bond is constructed between the aromatic amino acid Trp84 and one hydrogen of the aliphatic tail of the ligand. However, the overall recognition was greatly improved by the hydrophilic/hydrophobic interactions that appeared as a blue shadow in both ligand and receptor amino acids to score the highest binding free energy $-11.334281 \mathrm{Kcal} / \mathrm{mol}$.

\section{CONCLUSION}

A significant reduction of liver fibrosis was observed following treatment with losartan and enalapril or their combination in a murine model of hepatic fibrosis induced by S. mansoni infection. In addition, losartan could have beneficial effects as a promising antischistosomal agent by producing more reduction in liver and spleen indices, adult worm burden, tissue egg load, granuloma size, and count besides reduction of fibrosis in the affected liver.

\section{CONFLICT OF INTEREST}

Authors declare that they have no conflicts of interest.

\section{FUDING}

There is no financial support for this study.

\section{REFERENCES}

Alhusseiny SM, El-Beshbishi SN, Hashim MMA, ElNemr HEE, Handoussa AE (2017). A comparative study on the anti-schistosomal and hepatoprotective effects of vinpocetine and isosorbide-5-mononitrate on Schistosoma mansoni-infected mice. Acta Tropica. 176:114-125.

Attia YM, Elalkamy EF, Hammam OA, Mahmoud SS, El-Khatib AS (2013). Telmisartan, an AT1 receptor blocker and a PPAR gamma activator, alleviates liver fibrosis induced experimentally by Schistosoma mansoni infection. Parasites \& Vectors. 6(1):199.

Berhe N, Myrvang B, Gundersen SG (2008). Reversibility of schistosomal periportal thickening/fibrosis after praziquantel therapy: a twenty-six month follow-up study in Ethiopia. The American Journal of Tropical Medicine \& Hygiene. 78(2):228-34.

Botros SS, El-Badrawy N, Metwally AA, Khayyal MT (1986). Study of some immunopharmacological properties of praziquantel in experimental schistosomiasis mansoni. Annals of Tropical Medicine \& Parasitology. 80(2):189-196.

Cheever AW (1968). A quantitative post-mortem study of Schistosomiasis mansoni in man. The American Journal of Tropical Medicine \& Hygiene. 17(1):38-64.

El-Lakkany NM, El-Maadawy W, Ain-Shoka A, Badawy A, Hammam O, Ebeid F (2011). Potential antifibrotic effects of AT1 receptor antagonist, losartan, and/or praziquantel on 
acute and chronic experimental liver fibrosis induced by Schistosoma mansoni. Clinical and Experimental Pharmacology and Physiology. 38(10):695-704.

Fallon PG, Richardson EJ, McKenzie GJ, McKenzie ANJ (2000). Schistosome infection of transgenic mice defines distinct and contrasting pathogenic roles for IL-4 and IL-13: IL-13 Is a profibrotic agent. The Journal of Immunology. 164(5):2585.

Gönnert R, Andrews P (1977). Praziquantel, a new board-spectrum antischistosomal agent. Zeitschrift fur Parasitenkunde (Berlin, Germany). 52(2):129-150.

Gryseels B (2012). Schistosomiasis. Infectious Disease Clinics of North America. 26(2):38397.

Kim YM, Jeon E, Kim M, Lee J, Kim J (2008). Bradykinin-induced expression of $\alpha$-smooth muscle actin in human mesenchymal stem cells. Cellular signalling. 20:1882-1889.

Knodell RG, Ishak KG, Black WC, Chen TS, Craig R, Kaplowitz N, Kiernan TW, Wollman J (1981). Formulation and application of a numerical scoring system for assessing histological activity in asymptomatic chronic active hepatitis. Hepatology. 1(5):431-5.

Labute P (2008). The generalized Born/volume integral implicit solvent model: estimation of the free energy of hydration using London dispersion instead of atomic surface area. Journal of Computational Chemistry. 29(10):1693-8.

Lee UE, Friedman SL (2011). Mechanisms of hepatic fibrogenesis. Best practice \& research Clinical gastroenterology. 25(2):195-206.

Lescano SZ, Chieffi PP, Canhassi RR, Boulos M, Amato Neto V (2004). Antischistosomal activity of artemether in experimental Schistosomiasis mansoni. Revista de Saúde Pública. 38(1):715.

Liang YJ, Luo J, Yuan Q, Zheng D, Liu YP, Shi L, Zhou Y, Chen AL, Ren YY, Sun KY, Sun Y, Wang Y, Zhang ZS (2011). New Insight into the Antifibrotic Effects of Praziquantel on Mice in Infection with Schistosoma japonicum. PLOS ONE. 6(5):e20247.

Loverde PT, Osman A, Hinck A (2007). Schistosoma mansoni: TGF-beta signaling pathways. Experimental parasitology. 117(3):304-317.

Ma TK, Kam KK, Yan BP, Lam YY (2010). Reninangiotensin-aldosterone system blockade for cardiovascular diseases: current status. British Journal of Pharmacology. 160(6):127392.

Molecular operating environment (MOE) (2019). 01 9 (a drug discovery software platform ),
Chemical Computing Group Inc 1010 Sherbooke St. West, Suite\# 910, Montreal, QC, Canada, H3A 2R7, 2019.

Mormone E, George J, Nieto N (2011). Molecular pathogenesis of hepatic fibrosis and current therapeutic approaches. Chemico-Biological Interactions. 193(3):225-31.

Natesh R, Schwager SL, Evans HR, Sturrock ED, Acharya KR (2004). Structural details on the binding of antihypertensive drugs captopril and enalaprilat to human testicular angiotensin l-converting enzyme. Biochemistry. 43(27):8718-24.

Nurisso A, Bravo J, Carrupt PA, Daina A (2012). Molecular docking using the molecular lipophilicity potential as hydrophobic descriptor: Impact on GOLD docking performance. Journal of Chemical Information and Modeling. 52(5):1319-1327.

Parreira NA, Ramalho FS, Augusto MJ, Silva DM, Prado CM, Elias Júnior, Rodrigues $\mathrm{V}$, Ramalho LNZ (2018). The comparative efficacy of renin-angiotensin system blockers in schistosomal hepatic fibrosis. Experimental Parasitology. 191:9-18.

Rippe RA (1998). Life or death: the fate of the hepatic stellate cell following hepatic injury. Hepatology. 27(5):1447-8.

Schuppan D, Afdhal NH (2008). Liver cirrhosis. Lancet. 371(9615):838-51.

Shim KY, Eom YW, Kim MY, Kang SH, Baik SK (2018). Role of the renin-angiotensin system in hepatic fibrosis and portal hypertension. The Korean journal of internal medicine. 33(3):453-461.

Singh KP, Gerard HC, Hudson AP, Boros DL (2004). Expression of matrix metalloproteinases and their inhibitors during the resorption of schistosome egg-induced fibrosis in praziquantel-treated mice. Immunology. 111(3):343-352.

Smithers SR, Terry RJ (1965). The infection of laboratory hosts with cercariae of Schistosoma mansoni and the recovery of the adult worms. Parasitology. 55(4):695-700.

Sun M, Kisseleva T. 2015. Reversibility of liver fibrosis. Clinics and research in hepatology and gastroenterology 39 Suppl 1(0 1):S60S63.

Taman A, Alhusseiny SM, Saleh NE, Youssef MY, Mansour B, Massoud M, El-Beshbishi SN (2020a). Effect of a newly synthesized quinoline-based compound (PPQ-8) on murine schistosomiasis mansoni. Journal of Helminthology. 94:e123.

Taman A, Alhusseiny SM, El-Zayady WM, Elblihy AA, Mansour B, Massoud M, Youssef MY, Saleh 
NE (2020b). In vivo studies of the effect of PPQ-6, a quinoline-based agent against Schistosoma mansoni in mice. Experimental Parasitology. 215:107933.

Tanwar S, Rhodes F, Srivastava A, Trembling PM, Rosenberg WM (2020). Inflammation and fibrosis in chronic liver diseases including non-alcoholic fatty liver disease and hepatitis C. World journal of gastroenterology. 26(2):109-133.

Wei HS, Lu HM, Li DG, Zhan YT, Wang ZR, Huang X, Cheng JL, Xu QF (2000). The regulatory role of
AT 1 receptor on activated HSCs in hepatic fibrogenesis:effects of RAS inhibitors on hepatic fibrosis induced by $\mathrm{CCl}(4)$. World journal of gastroenterology. 6(6):824-828.

Wilson MS, Mentink-Kane MM, Pesce JT, Ramalingam TR, Thompson R, Wynn TA (2007). Immunopathology of schistosomiasis. Immunology \& Cell Biology. 85(2):148-54.

Zhang H, Unal H, Gati C, Han GW, Liu W, Zatsepin NA (2015). Structure of the Angiotensin Receptor Revealed by Serial Femtosecond Crystallography. Cell. 161(4):833-844. 


\section{Egyptian Association for Cancer Research (EACR)}

http://eacr.tanta.edu.eg/

EACR is an NGO society that was declared by the Ministry of Social Solidarity (Egypt) No. 1938 in 19/11/2014 based on the initiative of Prof. Mohamed Labib Salem, the current Chairman of EACR. EACR aims primarily to assist researchers, in particular young researchers in the field of cancer research through workshops, seminars and conferences. Its first international annual conference entitled "Anti-Cancer Drug Discovery" was successfully organized in April 2019 (http://acdd.tanta.edu.eg). Additionally, EACR aims to raise the awareness of the society about the importance of scientific research in the field of cancer research in prediction, early diagnosis and treatment of cancer. EACR is also keen to outreach the scientific community with periodicals and news on cancer research including peer-reviewed scientific journals for the publication of cutting-edge research. The official scientific journal of EACR is "International Journal of Cancer and biomedical Research (IJCBR: https://jcbr.journals.ekb.eg) was successfully issued in 2017 and has been sponsored by the Egyptian Knowledge Bank (EKB: www.ekb.eg).

\section{EACR Chairman,}

Prof. Mohamed Labib Salem, PhD

Professor of Immunology

Faculty of Science, Tanta Universiy, Egypt 
International Journal of Cancer and Biomedical Research (IJCBR), a publication of the Egyptian Association for Cancer Research (EACR), is a peer-reviewed online journal published quarterly. The journal allows free access (Open Access) to its contents and permits authors to self-archive a final accepted version of the articles on any OAl-compliant institutional / subject-based repository.

\section{Aim And Scope}

Aim: The main aim of IJCBR is to attract the best research in animal and human biology in health and diseases from across the spectrum of the biomedical sciences at the molecular, cellular, organ, and whole animal levels especially those that are related to cancer research, including causes, prediction, diagnosis, prognosis and therapy.

Scope: It is essential reading for all researchers interested in biochemistry, cancer, microbiology, nutrition, physiology, genetics, immunology, epidemiology, medical economics, human biology, bioinformatics, biotechnology, nanotechnology, and disease modeling.

\section{Publication Ethics}

Researchers should conduct their research from research proposal to publication in line with the best practices and codes of conduct of relevant professional bodies and/or national and international regulatory bodies. IJCBR accepts manuscripts prepared in accordance with the "Uniform Requirements for Submission of Manuscripts for Biomedical Journals adopted by the International Committee of Medical Journal Editors (ICMJE) and the Committee on Publication Ethics (COPE). Details of ICMJE and COPE are available at http://www.icmje.org/ and http://publicationethics.org/

\section{Peer Review Process}

After the IJCBR editor receives a manuscript, the first step is to confirm that the manuscript meets the journal's rules for content and format, including similarity check (plagiarism) which should be less than $25 \%$. If the manuscript meets the journal's rules, the editor then assign it to the double-blind peer review process. The IJCBR editor send the manuscript to at least two experts in the field for RIGOROUS scientific evaluation. The experts called peer reviewers - will then prepare a report that assesses the manuscript and return it to the editor through the IJCBR portal. Upon the first submission, this reviewing process takes about 4 to 6 weeks. After reading the peer reviewer's report, the editor will decide one of the following four options:

1. Reject the manuscript.

2. Accept the manuscript

3. Ask the authors to revise and resubmit the manuscript after responding to the peer reviewers' feedback.

4. Ask for peer-review from additional reviewers.

If the authors resubmit the manuscript, the IJCBR editor will ask the same peer-reviewers to look over the manuscript again to confirm that their concerns have been addressed. This is called re-review process. This second revision (if applicable) takes about another 4 to 6 weeks. At this point, the abstract of the article appears in press. The online publication (the PDF format) of the final version of the manuscript takes from 2 to 4 weeks. As such, the total publication cycle takes from 2 to 4 months. This cycle can be reduced to 4 to 6 weeks (fast track publication) for the manuscripts with outstanding findings.

The peer-review process used by IJCBR includes comments on errors in the study's methods or analysis that raise questions about the findings, or sections that need clearer explanations. The peer-review process also includes the importance and novelty of the manuscript and its interest to the journal's audience. The IJCBR uses double-blind review, which means that both the reviewers and authors identities are concealed from the reviewers, and vice versa, throughout the review process. To facilitate this, authors need to submit a Title Page containing the Authors details and Blinded Manuscript with no author details as 2 separate files. 


\section{Publisher}

The International Journal of Cancer and Biomedical Research (IJCBR) is an International and interdisciplinary journal of preclinical and clinical studies in the area of cancer and biomedical research. It is a peer-reviewed journal in English, published quarterly (in March, June, September, and December) by the Egyptian Association for Cancer Research (EACR) in both print and online formats (4 issues making a volume). Special issues or supplements may also be produced from time to time upon agreement with the Editorial Board.

\section{Scope}

The main aim of IJCBR is to attract the best research in animal and human biology in health and diseases from across the spectrum of the biomedical sciences at the molecular, cellular, organ, and whole animal levels especially those that are related to cancer research, including causes, prediction, diagnosis, prognosis and therapy.

\section{Publication Fees}

The journal does charge for submission, processing or publication of manuscripts (2000 LE for Egyptians or $\$ 300$ for non-Egyptians; EACR members receive 15\% discount on publication). Of them Peer-review fees (300 LE) should be paid on submission (non-refundable). For the fast track production of the accepted manuscript, another $500 \mathrm{LE}$ is paid.

General specifications for different types of article

- Submitted manuscripts should not have been published previously, except in a limited form (e.g. short communication to a symposium or as part of MSc or PhD theses) and should not be under consideration for publication by other journals.

- All co-authors should agree with the content of the manuscript. Authors must have obtained permission to use any copyrighted material in the manuscript before submission.

\section{IJCBR publishes different types of articles}

- Original Article (6000 words with $\mathbf{4}$ tables and $\mathbf{4}$ figures, maximum $\mathbf{8}$ display items): Articles with novel findings are the target of IJCBR. Articles presenting a detailed description of a new technique, comparison of existing methods, meta-analyses with comprehensive and in-depth discussion are considered. Papers in a numbered series are not accepted unless all are submitted at the same time.

- Short communications or case study (3000 words with 4 display items): Short communications present exceptionally exciting, novel or timely contents are considered. They will be peer-reviewed in the same way as research papers. The references are restricted to 15 .

- Reviews or systematic review (9000 words with $\mathbf{1 0}$ display items): They are invited by the Editorial Board or unsolicited. Review articles have to be contemporary and comprehensive and add information to the knowledge. Sharp critical analyses of novel data or concepts are encouraged. When relevant, a statistical analysis of data and a meta-analysis approach are recommended.

- Opinion papers, letter to the editor or comment to the editor (1500 words with $\mathbf{2}$ display items): They are submitted by invitation of the Editorial Board. They are short papers, which aim to inform scientists, industry, and the public and policymakers about cutting-edge issues in research or the impact of research. They reflect the opinion of their authors who bear full responsibility of the published paper. The references are restricted to 10 .

- Conference/Symposium papers: The journal will consider for publication the results of original work and critical reviews that are presented at conferences/symposia. Symposium organizers who wish to publish bundles of papers from a symposium/conference in IJCBR should first contact the Editor-inChief of the IJCBR (EACR@unv.tanta.edu.eg) for agreement. Supplementary material can be proposed and will be made available online. The responsibility for the preparation of a paper in a form suitable for publication lies with the author.

- Thesis: IJCBR can publish the summary and abstract of Master and PhD theses in a special issue. 
English: Good quality of written English is required. Spelling may be in British or American English but must be consistent throughout the paper. Care should be exercised in the use of biological terminology that is ill-defined or of local familiarity only. We recommend that authors have their manuscripts checked by an English language native speaker before submission.

Manuscript layout: Manuscripts should be prepared using a standard word processing program and presented in a clear readable format with easily identified sections and headings. The manuscript layout is based on the following directions.

- The main text contains Title, Abstract, Keywords, Introduction, Material and Methods, Results, Discussion, References, Tables, figures.

- The title needs to be concise and informative. Use bold, with an initial capital for the first word only and for words that ordinarily take capitals

- Short (running) title (max 80 characters including spacing).

- The article text should be typed with double-line spacing with wide margins $(2.5 \mathrm{~cm})$.

- The lines must be continuously numbered; the pages must also be numbered.

- Font Calibri 12 should be used for the text, and 12 for the tables, figure legends and references.

- The sections should typically be assembled in the following order:

- Title page contains title, authors' names, full affiliations, acknowledgements and the corresponding author's contacts and Short title.

Abstract (max 250 words, single paragraph): The abstract should be complete and understandable without citation, references, table or figure. Use structured abstract: Background, Aim, Materials \& Methods, Results and Conclusion. The context and the rationale of the study are presented succinctly to support the objectives. The experimental methods and main results are summarized but should not be overburdened by numerical values or probability values. The abstract ends with a short and clear conclusion.

Keywords: Up to five short and specific keywords should complement the title with respect to indicating the subject of the paper in alphabetic order.

Introduction: The introduction briefly outlines the context of the work, presents the current issues that the authors are addressing and the rationale to support the objectives, and clearly defines the objectives.

Material and methods: Material and methods should be described in sufficient details so that others can repeat the experiment. Reference to previously published work may be used to give methodological details, provided that said publications are readily accessible and in English. The code of ethics should be followed for all experiments use animals or human samples.

Statistical analysis of results: The statistical design and the models of statistical analysis must be described, as well as each of the statistical methods used. Sufficient statistical details must be given to allow replication of the statistical analysis. The experimental unit should be defined (e.g. individual or group of animals).

Results: Data are presented as tables and figures. Brief description of the results for each table and figure should be presented. Unpublished data can be mentioned when necessary.

Discussion: Should be separate from the Results section and should focus only on intra- and inter-data discussion (the data in the results section) as well as with the relative data in the literature. Don't repeat information already presented in the Introduction section. Start the first paragraph in the Discussion with a paragraph stating the rationale behind the study, the objectives and the main findings. End Discussion with a short conclusion.

Acknowledgements: In this section, the authors may acknowledge (briefly) their support staff.

Conflict of interest: All papers with a potential conflict of interest must include a description/explanation in a separate heading.

Funding details: The authors should state the source of findings of the study (with research funder and/or grant number). If no fund, the authors should state that the study is self-funded. 


\section{References}

Citation of references: In the text, references should be cited by the author(s) surname(s) and the year of publication (e.g. Salem, 2020). References with two authors should be cited with both surnames (e.g. Salem and Meshrif, 2021). References with three or more authors should be cited with the first author followed by et al. (in italics; e.g. Salem et al., 2021). Names of organizations used as authors (e.g. Food and Drug Administration) should be written out in full in the list of references and on the first mention in the text. Subsequent mentions may be abbreviated (e.g. FDA).

- List of references. Literature cited should be listed in alphabetical order by authors' names. It is the author's responsibility to ensure that all references are correct. All authors should be written and so the full journal name.

- References from journal articles are formatted in APA as this example: Al-Amoudi WM (2018). Toxic effects of Lambda-cyhalothrin on the rat thyroid. Involvement of oxidative stress and ameliorative effect of ginger extract. Toxicology Reports, 5: 728-736.

- References from books or official reports are formatted as this example. Kebreab E, Dijkstra ANM, Bannink A, Gerrits WJJ, \& France J (2006). Nutrient digestion and utilization in farm animals. CABI Publishing. Wallingford, UK.

- References from chapters or parts of books are formatted as this example. Nozière $P, \&$ Hoch $T$ (2006). Modelling fluxes of volatile fatty acids from rumen to portal blood. In: Nutrient digestion and utilization in farm animals (Kebreab E, Dijkstra ANM, Bannink A, Gerrits WJJ \& France J, eds.), pp. 40-47. CABI Publishing. Wallingford, UK.

Tables:

The data should be presented in tables or in graphs, not both.

- Each table should be placed on a separate page at the end of the main text.

- Tables are numbered consecutively using Arabic numbering. They are referred to as Table 1 , Table 2, etc., with capital ' $T$ ', no italics

- Each table has its explanatory caption. The caption is sufficient to permit the table to be understood without reference to the text.

- Abbreviations used in tables/figures have to be defined either as footnotes or in the caption.

Figures

- Package the figures in a single PowerPoint file. Each figure in a separate slide.

- Figure size should be readable in a width of approximately 8-175 $\mathrm{mm}$ (i.e. the maximum size of printing over two columns).

- Ensure that the font size is large enough to be readable at the final print size, use Calibri font to ensure that they are consistent throughout the figures.

- The figures should preferably be provided as TIFF or EPS files.

- The resolutions of figures must be at least $300 \mathrm{dpi}$.

- Preparation of images for a manuscript: For guidance, we refer to the Journal of Cell Biology's instructions to authors (http://jcb.rupress.org/site/misc/ifora.xhtml\#image_aquisition).

- If a cropped image is included in the main text of a paper (e.g. a few lanes of a gel), display the full original image, including the appropriate controls, the molecular size ladder and/or the scale as relevant, as a single figure in a Supplementary Material file to facilitate peer-review and for subsequent online publication.

- Supplementary material is submitted along with the main manuscript in a separate file and identified at uploading as "Supplementary File - for Online Publication Only" The title of the article is included at the top of the supplementary material.

Corresponding author's guidelines: Upon acceptance the corresponding author is required to send his/her recent formal photo to be attached to the front page of the article. 


\title{
International Journal of Cancer \& Biomedical Research
}

(IJCBR) Online ISSN 2682-2628

\author{
Editor-in-Chief \\ Mohamed Labib Salem, PhD \\ Tanta University, Egypt
}

\begin{tabular}{l} 
EACR Board \\
\hline Nehal Elmashad, MD \\
Tanta University, Egypt \\
Nabil Mohy Eldin, PhD \\
Kafrelsheikh University, Egypt \\
Doaa Al-Ghareeb, PhD \\
Alexandria University, Egypt \\
Abdel-Aziz Zidan, PhD \\
Damanhour University, Egypt
\end{tabular}

\begin{tabular}{l} 
Managing Editor \\
\hline Wesam Meshrif, PhD \\
Tanta University, Egypt \\
Sohaila Galal, PhD \\
Tanta University, Egypt \\
Production and Contact \\
\hline Hamdi Kandil \\
Tanta University, Egypt \\
Email: ljcbr100@gmail.com
\end{tabular}

\section{Advisory Board}

Alberto Montero, MD

Taussig Cancer Center, Cleveland,

USA

Yi Zhang, MD

Zhengzhou University, China

Mark Robunstein, Ph D

Medical University of South

Carolina, USA

Mohsen Farid, Ph D

Derby University, USA

Natarajan Muthusamy, Ph D

Ohio State University, USA

Hideki Kasuya, MD

Nagoya University, Japan

Sherif El-Khamisy, Ph D

Sheffield University, UK

Mohamed Ghanem, Ph D

Kafr Elshikh University, Egypt

Sayed Bakry, Ph D

Alazhar University, Egypt

Sameh Ali, Ph D

Nationa Liver Institute, Egypt

Gamal Badr, Ph D

Assuit University, Egypt

Nadia Hamdy, Pharm D

Ain Shams University, Egypt

\section{Editorial Board}

\section{Clinical studies}

Hesham Tawfik, MD

Tanta University, Egypt

Mohamed Attia, MD

Tanta University, Egypt

Mohamed Elshanshory, MD

Tanta University, Egypt

Essam Elshiekh, MD

Tanta Cancer Center, Egypt

Rasha Eraky, MD

Tanta University, Egypt

Shaima Abou-Kjatwa, MD

Tanta University, Egypt

Marcela Diaz, MD

Cleveland Clinic Foundation, USA

Mohamed Abou-El-Enein, MD

Charité Universitätsmedizin Berlin,

Germany
Alaa Eldin Almostafa, MD

McGill University, Canada

Olfat Gadallah, MD

Tanta University, Egypt

Nagla Sarhan, MD

Tanta University, Egypt

Naglaa Fathy, Pharm D

Zagazik University, Egypt

Mohamed Salama, MD

Mansoura University, Egypt

Mona Marie, MD

Alexandria University, Egypt

Preclinical studies

Mostafa El-Sheekh

Tanta University, Egypt

El-Refai Kenawy, Ph D

Tanta University, Egypt

Mohamed Noureldin, Ph D

Banaha University, Egypt

Yousry Albolkiny, Ph D

Tanta University, Egypt

Elsayed Salim, Ph D

Tanta University, Egypt

Shengdian Wang, Ph D

Chinese Academy of Sciences,

China

Sabry El Naggar, Ph D

Tnata Univesity, Egypr

Faris Alenzi, Ph D

Prince Sattam bin Abdulaziz

University, KSA

Ibrahim El-Sayed, Ph D

Menoufia University, Egypt

Tarek Aboul-Fadl, Ph D

Assiut University, Egypt

Rabab Khairat, Ph D

National Research Center,

Giza, Egypt

Wael Lotfy, Ph D

Alexandria University, Egypt

Ashraf Tabll, Ph D

National Research Center, Egypt

Nahla Shoukry, Ph D

Suez University, Egypt
Medhat Eldenary, Ph D

Tanta University, Egypt

Azza Hasan, Ph D

Menufia University, Egypt

Nanees Gamal Eldin, Ph D

Tanta University, Egypt

Mohamed Mansour, UK

Sabbah Hammoury, Ph D

Alexandria Ayadi Almostaqba

Oncology Hospital, Egypt

Nehal Aboulfotoh, Ph D

Zewail City for Science and

Technology, Cairo, Egypt

Amir Elkhami, Ph D

Galaxo, San Francisco, USA

Ahmed Alzohairy, Ph D

Zagazi University, Egypt

Wgady Khalil, Ph D

National Research Center, Egypt

Amr Amin, Ph D

United Arab Emirates

University, UAE

AbdelRahman Zekri, Ph D

National Cancer Institute, Egypt

Hussein Khamis, Ph D

Alexandria University, Egypt

Magdy Mahfouz, Ph D

Kafr Elsheikh University, Egypt

Ehab Elbedewey, Ph D

Tanta University, Egypt

Abeer Badr, Ph D

Cairo University, Egypt

Mamdooh Ghoneum, Ph D

Charles Drew University of

Medicine \& Science, USA

Haiam Abou Elela, Ph D

National Institute of Oceanography and Fisherie, Egypt

Maha EL-Demellawi, Ph D City for Scientific Research \&

Technology Applications, Egypt

Desouky Abd-El-Haleem, Ph D

City for Scientific Research \&

Technology Applications, Egypt 